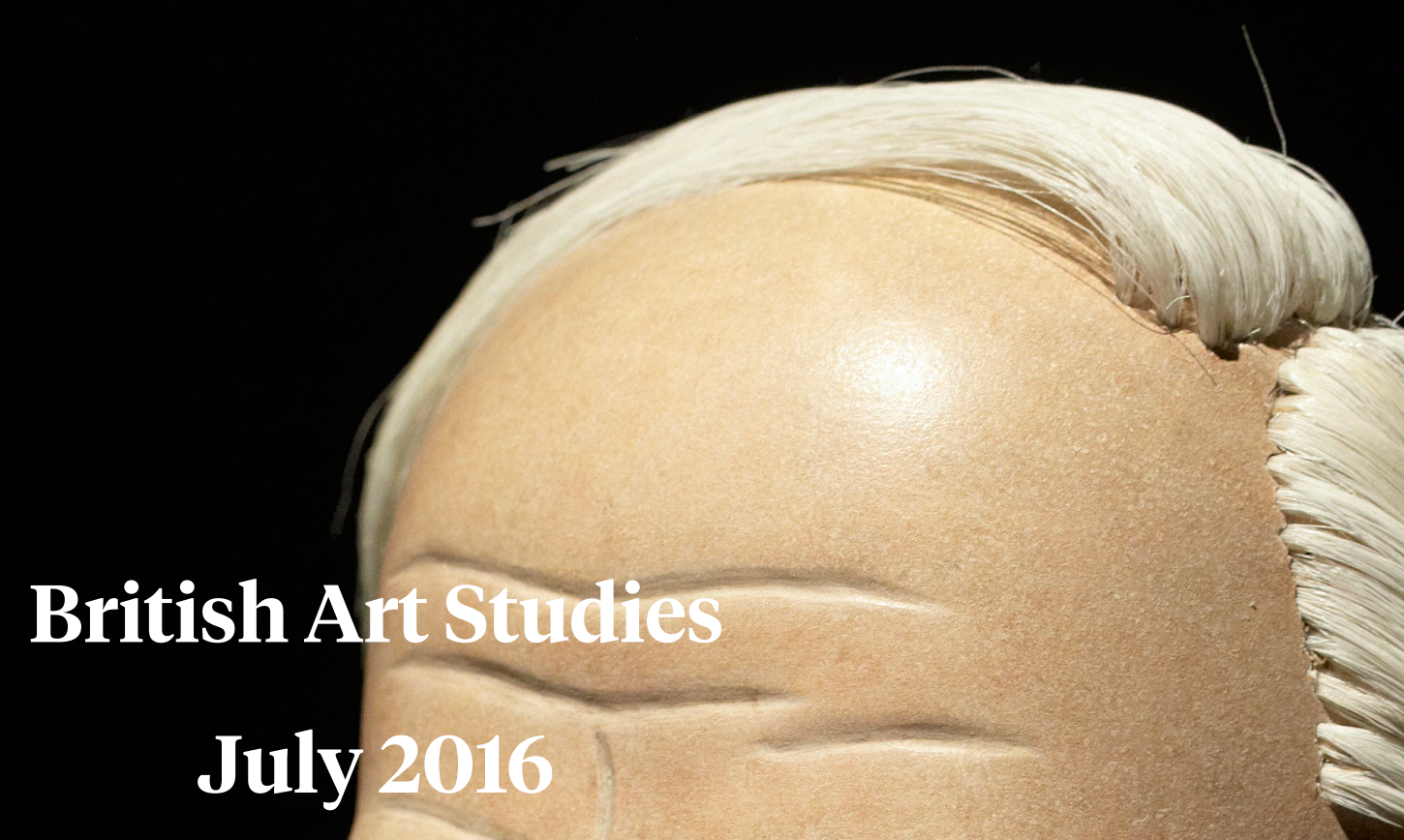

British Sculpture Abroad, $1945-2000$

Edited by Penelope Curtis and Martina Droth 
British Art Studies

Issue 3, published 4 July 2016

British Sculpture Abroad, 1945 - 2000

Edited by Penelope Curtis and Martina Droth

Cover image: Installation View, Simon Starling, Project for a Masquerade (Hiroshima), 2010-11, $16 \mathrm{~mm}$ film transferred to digital (25 minutes, 45 seconds), wooden masks, cast bronze masks, bowler hat, metals stands, suspended mirror, suspended screen, HD projector, media player, and speakers. Dimensions variable. Digital image courtesy of the artist

PDF generated on 14 April 2022

Note: British Art Studies is a digital publication and intended to be experienced online and referenced digitally. PDFs are provided for ease of reading offline. Please do not reference the PDF in academic citations: we recommend the use of DOIs (digital object identifiers) provided within the online article. These unique alphanumeric strings identify content and provide a persistent link to a location on the internet. A DOI is guaranteed never to change, so you can use it to link permanently to electronic documents with confidence.

Published by:

Paul Mellon Centre 16 Bedford Square London, WC1B 3JA https://www.paul-mellon-centre.ac.uk

In partnership with:

Yale Center for British Art 1080 Chapel Street New Haven, Connecticut https://britishart.yale.edu

ISSN: 2058-5462

DOI: $10.17658 /$ issn.2058-5462

URL: https://www.britishartstudies.ac.uk

Editorial team: https://www.britishartstudies.ac.uk/about/editorial-team Advisory board: https://www.britishartstudies.ac.uk/about/advisory-board

Produced in the United Kingdom. 


\section{Contents}

Renewing the New: British Sculpture in the 1980s, Greg Hilty 


\title{
Renewing the New: British Sculpture in the 1980s
}

\author{
Greg Hilty
}

Abstract

Greg Hilty introduces the case studies in his 1980s section of "British Sculpture Abroad". He also points to two exemplary instances of British sculpture's expansion onto an ever wider global stage: Tony Cragg in Warsaw in 1988 and Richard Long in Paris in 1989.

\section{Authors}

Curatorial Director at Lisson Gallery, London

\section{Cite as}

Greg Hilty, "Renewing the New: British Sculpture in the 1980s", British Art Studies, Issue 3, https://dx.doi.org/10.17658/issn.2058-5462/issue-03/ghilty 


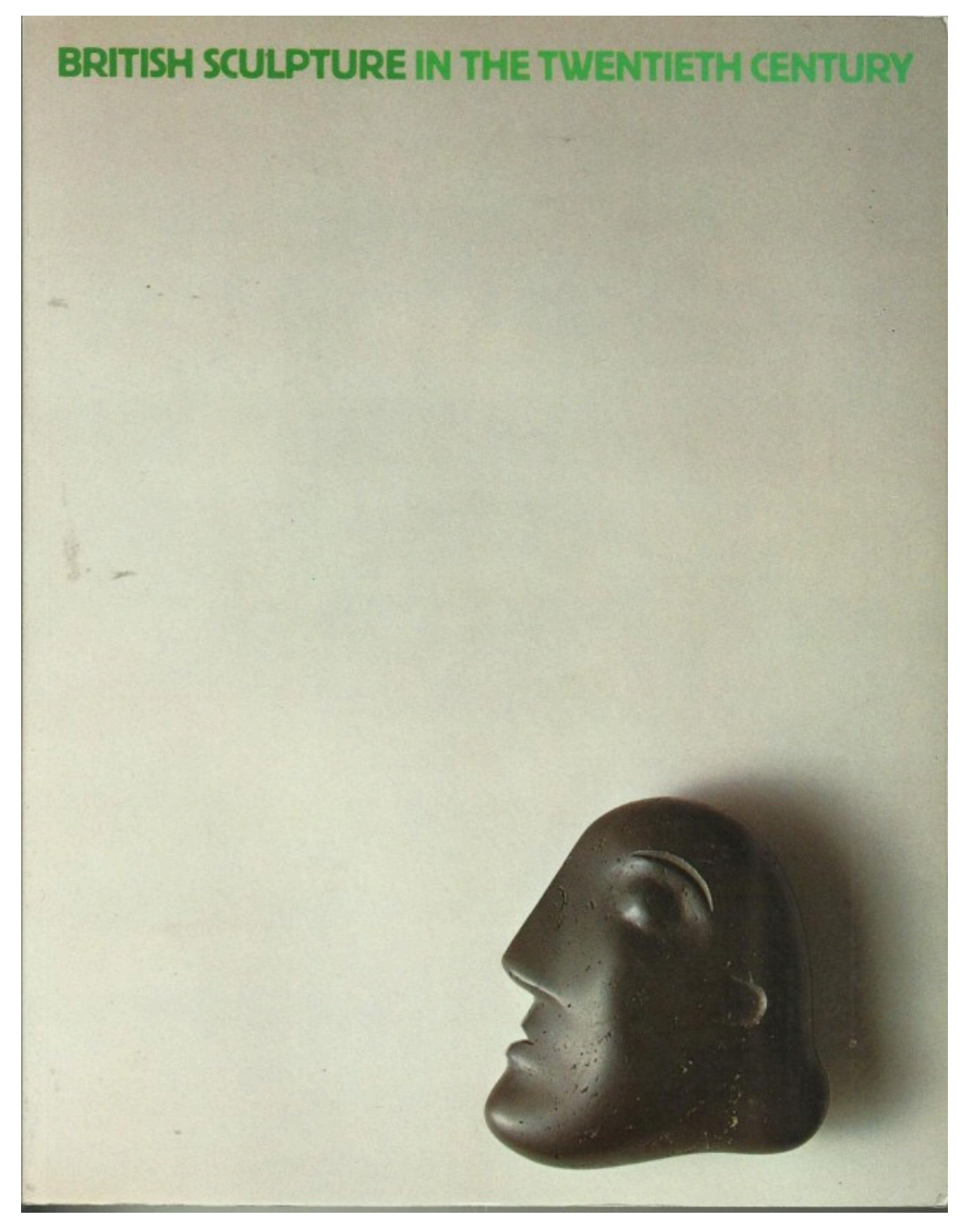

Figure 1.

Exhibition catalogue, British Sculpture in the Twentieth Century, Sandy Nairne and Nicholas Serota (eds), (London: Whitechapel Art Gallery, 1981)

One of the early defining exhibitions held in 1980s Britain excluded sculpture from its frame of reference yet presaged a shift in taste and practice that would become dominant through the decade. A New Spirit in Painting was selected by Christos Joachimides, Norman Rosenthal, and Nicholas Serota and presented at the Royal Academy in the spring of 1981. 1 The exhibition, as well as asserting a revival of interest in traditional painting as a medium, focused on key practitioners, on narrative and figurative content, and on national classifications. Later that year the Whitechapel Art Gallery presented its two-part survey British Sculpture in the Twentieth Century. ${ }^{2}$ As its title suggests this was an overview of the century but signalled also a reconsideration of Modernism's traditions, inevitably in contradistinction to the experiments into the "expanded field" of sculpture that had marked the 
previous decade. The art critic John McEwen used the language of the day when he spoke of the "new spirit", "zest", and "eclecticism" of the exhibition (alongside its "inadequacies"). $\underline{3}$

A new generation of sculptors, trained in the rigours and inspired by the ambitions of conceptual and minimal practice, but unafraid to direct their disciplines to wider material and content considerations, quickly established itself through a rapid series of group exhibitions in the UK and Europe. 4 These exhibitions provided a consolidated platform for the object- and image-based work of a group of artists who had come to maturity in the 1970 s and early 1980s. The essays in this section consider different ways in which the influence of these artists extended beyond the UK to become the dominant "school" of British art during the decade. There were, to be sure, other highly significant practices, groupings, and individuals, but in the context of this journal a focused analysis of the emergence of the "New British Sculptors" and the dissemination of their work is essential.

Nick Baker's quantitative analysis gives fascinating objective evidence of the surge of interest in British art and, especially, the new generation of sculptors internationally in the 1980s.

Anthony Bond-a key figure in the Australian contemporary art world in the 1980s - writes about The British Art Show organized by the British Council which travelled to museums in Australia and New Zealand in 1985-86. Describing the fresh nature of the work shown compared to the abstract sculpture of a previous generation, he picks up on characteristics of narrative, affect, and humour in the work shown, tending towards a "democratization of art" and its reception. Bond followed this exhibition with deeper personal and institutional engagements with a number of its key artists through repeat visits and residencies.

Bond attests to the highly active role of the Visual Arts Department of the British Council which was crucial during this period, both instigating initiatives and supporting projects in partnership with international partners. The Council's key platform, the British Pavilion at the Venice Biennale, gave three of its five slots during the decade to sculptors and supported numerous group shows globally. $\underline{5}$

Mary Jane Jacob (whose early research into British sculpture was supported by the British Council) writes about her exhibition A Quiet Revolution: British Sculpture since 1965, which she co-curated with Graham Beal. Their 1987 project, a few years into the phenomenon of "New British Sculpture", took a slightly longer view and focused on six artists of successive generations, pointing to the overlapping continuity and innovation in British art over two decades, including their common academic backgrounds, and identified 
certain shared characteristics of reticence and introversion underlying the work, which contrasts with the brasher, more Pop culture associations of the earlier group shows. Jacob and Beal's project was exemplary in demonstrating a considered and specific curatorial perspective on an artistic moment that was still taking shape.

Julian Heynen writes of his close working relationship with Richard Deacon, focusing on the artist's dual exhibitions within the highly specific programme of the Haus Lange and Haus Esters which Heynen directed from 1981 as key venues in the Krefelder Landesmuseen. The programme concentrated on a tightly associated group of artists of similar generation and often friendship, including Juan Muñoz, Harald Klingelhöller, Thomas Schütte, and Richard Deacon. Heynen shows how Deacon, while remaining based in the UK, established strong individual artistic and curatorial relationships in continental Europe. Deacon was notable for his participation in the Skulptur Projekte Münster in 1987, alongside only two other British Artists, lan Hamilton Finlay and Shirazeh Houshiary.

The galleries and institutions of the Rhineland were important for most of the New British Sculptors: their leading figure, Tony Cragg, moved his studio from Britain to Wuppertal in 1977 and became one of the region's most prominent artists. This did not stop him simultaneously representing "British" art and sculpture in particular. In 1988, he represented Great Britain at the Venice Biennale and later that year won the Turner Prize. Less lauded, but nevertheless significant, was his modest show at the small but influential Foksal Gallery in Warsaw in the same year. The Foksal, as well as championing the most innovative Polish artists, was key in inviting leading international figures to show there during the years of Poland's cultural and political opening up. For Cragg, as well as the intrinsic interest of showing in such a dynamic context, this project awakened him to the possibilities and value of pioneering relationships with institutions in territories that many would have seen as on the margins of the art world. 


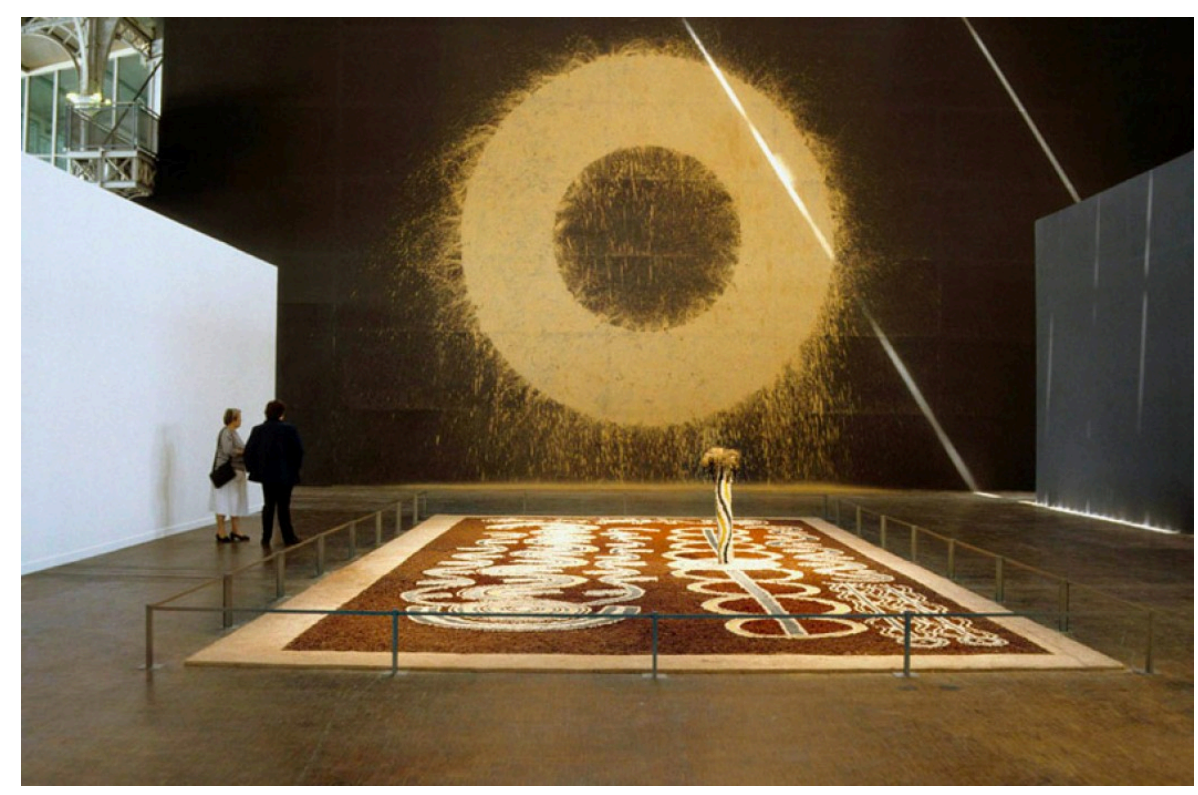

Figure 2.

Richard Long, Red Earth Circle, 1989, and Paddy Japaljarri Sims, Paddy Japaljarri Stewart, Neville Japangardi Poulson, Francis Jupurrurla Kelly, Paddy Jupurrurla Nelson, Franck Bronson Jakamarra Nelson, Towser Jakamarra Walker and Yuendumu community, Yam Dreaming, 1989, installed in the Magiciens de la Terre exhibition, Grande Halle de la Villette, Paris, 1989 Digital image courtesy of Centre Pompidou / MNAM$\mathrm{CCl} / \mathrm{Bib}$. Kandinsky / Photo: Béatrice Hatala

The artistic decade closed in 1989 with the paradigm-shifting exhibition Magiciens de la Terre in Paris, for which Jean-Hubert Martin and his curatorial team selected fifty artists from "centres" and fifty artists from "margins" of the art world, notionally on equal terms whether established within the hierarchies of Western art or local traditions of visual culture. The problematics of the project were many and are well documented. ${ }^{6}$ At the same time the initiative heralded a significant, if inevitably contested, expansion of the art world from its perceived charmed inner circle. One of the exhibition's most resonant juxtapositions was the presentation at the Grande Halle de la Villette of two site specific works: Richard Long's Red Earth Circle (1989) and Yam Dreaming by seven members of the Yuendumu community in Central Australia-Francis Jupurrurla Kelly, Frank Bronson Jakamarra Nelson, Paddy Jupurrurla Nelson, Neville Japangardi Poulson, Paddy Japaljarri Sims, Paddy Japaljarri Stewart, and Towser Jakamarra Walker. The two works on a comparable spectacular scale were viewable (and often photographed) within the same visual field. They were both symbolic representations of the earth, both shared the formal similarity of vibrating circular motifs, and were handmade from materials taken from the earth. Long had had close connections with Australia since he was first invited to a residency there by John Kaldor in 1977 . The Yuendumu community artists would present a related major work in Europe just a few years later in the exhibition Aratjara: The Art of the First Australians shown at museums in 
Germany, Denmark, and the United Kingdom. The iconic pairing of these two works at La Villette remains a ground-breaking artistic dialogue, pointing the way to the increasing range and depth of globalization of individual artistic practice and curation in the decades that have followed, in which British artists would play an important role.

\section{Footnotes}

1 The exhibition ran from 15 Jan. to 18 March 1981.

2 The exhibition ran from 11 Sept. 1981-24 Jan. 1982.

3 John McEwen, “London, Whitechapel Art Gallery, British Sculpture in the Twentieth Century", The Burlington Magazine 124, no. 948 (March 1982): 183.

$4 \quad$ Notable among these were: British Sculpture Now, Kunstmuseum Luzern, Lucerne, Switzerland, 1982; Objects and Figures: New Sculpture in Britain, Fruitmarket Gallery, Edinburgh, 1981; Objects and Sculpture: Richard Deacon, Antony Gormley, Anish Kapoor, Peter Randall-Page, Institute of Contemporary Arts, London, and Arnolfini Gallery, Bristol, 1981; The Sculpture Show, Serpentine Gallery and Hayward Gallery, London, 1983.

$\underline{5} \quad$ These were Nicholas Pope (with Tim Head) in 1980; Barry Flanagan in 1982; and Tony Cragg in 1988.

6 See, particularly, Lucy Steeds, ed., Making Art Global (Part 2): "Magiciens de la Terre" 1989 (London: Afterall Books, 2013).

\section{Bibliography}

McEwen, John. "London, Whitechapel Art Gallery, British Sculpture in the Twentieth Century." The Burlington Magazine 124, no. 948 (March 1982): 183.

Steeds, Lucy, ed. Making Art Global (Part 2): “Magiciens de la Terre” 1989. London: Afterall Books, 2013. 


\section{Licensing}

The Publishers of British Art Studies are committed to supporting scholarship on British art and architecture of all periods. This publication is made available free of charge at https://www.britishartstudies.ac.uk. We ask users to identify the use of materials made available through this website and to provide an appropriate credit to the to the author and the publication, so that others may find and use our resources.

Except where otherwise noted, this work is licensed under a Creative Commons Attribution-NonCommercial 2.0 UK: England \& Wales Licence (CC BY-NC 2.0 UK). To view a copy of this license, visit https://creativecommons.org/licenses/by-nc/2.0/uk/ or send a letter to Creative Commons, PO Box 1866, Mountain View, CA 94042, USA.

The Publishers fully support the protection of intellectual property and are committed to complying with, and strictly adhering to, all applicable copyright law. In many cases, copyright or other proprietary rights may be held by individuals or entities other than, or in addition to, the Publishers. If a work or a photographic image is still protected by copyright, you must cite the relevant copyright information when using the image and comply with all other terms or restrictions that may be applicable to that material.

In some cases, exceptions to copyright that permit limited use of protected works without the permission of the copyright owner may have be applied. We are confident that we have carried out due diligence in our use of copyrighted material as required, but we apologise for any inadvertent infringement of rights.

Digital copies of resources are made accessible for research for one of the following reasons:

- they are in the public domain;

- the rights are owned by the Publishers;

- we make them accessible under an exception or limitation to UK copyright law, as outlined in the Copyright, Designs and Patents Act 1988 (as amended);

- we have permission to make them accessible;

- or, there are no known restrictions on use.

If you believe that we have made a mistake and wish for your material to be removed from our site, please contact us at copyright@paul-mellon-centre.ac.uk.

Please include the following information with your request:

- Name and contact information, including email address and phone number.

- Identification of the resource for consideration of removal. Providing URLs in your communication will help us locate content quickly.

- The reason for the request.

The Publishers respond promptly, normally within 21 business days. We may remove the resource from our site while we assess the validity of the request. Upon completion of the assessment, we will take appropriate action and communicate that action to you. 